\title{
El constructor de ferrocarriles Henry Meiggs ${ }^{(*)}$
}

Por E. W. MIDDENDORF

Como los últimos empréstitos del Perú se levantaron a base de la pignoración de los yacimientos guaneros, y sólo pudieron ser emitidos en razón de una errónea idea de la cantidad existente, la aplicación de este dinero pertenece, pues, a la historia del guano. La falta de medios de transporte y las dificultades de las "condiciones del suelo, fueron en todo tiempo los impedimentos principales que se oponían al desenvoivimiento económico del Perú, desde siempre. En un país cortado por montañas elevadas, profundas gargantas y secoj arenales en la costa; cubierto en el interior por tupidas y húmedas selvas, los pueblos, inmensamente alejados entre sí, sólo estaban unidos por caminos de herradura, sin que se pudiera llevar por éstos ni medios de cultura a los distantes y fértiles valles, ni traer de ellos sus productos al mercado. Aunque los caminos de herradura fueren reemplazados por carreteras, no se habría remediado suficientemente el mal, lo que parece ser sólo posible con ferrocarriles, que abrirían al tráfico las regiones situadas en la sierra y en la vertiente oriental, haciendo remunerativo el trabajo en ellas. A comienzos del año cincuenta, fueron inaugurados los primeros ferroca-

(*) Tomado de la obra de E. W. Middendorf: Perú, observaciones y estudios sobre el pafs y sus habltantes, durante una permanencla de 25 afios. 
rriles en el país, de Lima a las ciudades portuarias del Callao y Chorrillos; luego siguió la línea de Arica a Tacna, el ferrocarril salitrero de Arica hacia Noría; en el Norte, de Salaverry a Truijillo, y otros más. Todos estos ferrocarriles atravesaban regiones de costa y como no encontraron en su construcciór? dificultades que vencer, y como ellos ofrecían más o menos buenas perspectivas para producir una renta correspondiente al capital invertido, se constituyeron, pues, por obra de empresa privada. No era de esperarse, sin embargo, que una obra semejante, pero que traspusiese la cordillera, pudiera llevarse a cabo, pues en ella los costos de construcción eran presumiblemente tan grandes, tan rala y tan pobre la población, que no se podía esperar un beneficio de su explotación en muchos años. Por eso es que estos ferrocarriles no podían ser construídos sino con dinero del Estado, y como ellos eran los más importantes para la explotación de Jas regiones del interior, el deseo de todas las personas serias y sensatas, era que se llegase a realizar. A este anhelo vinieron luego a sumarse todos aquellos que aspiraban a enriquecerse a costas del Estado, $y$ a quienes les era, por último, indiferente que una empresa significase utilidad o periuicio para el país, con tal de que ellos mismos sacasen provecho, o sea la clase más numerosa de los políticos más holgazanes $\mathrm{v}$ de los pobres diablos, una multitud de empleados de gobierno y de miembros deI Congreso, a todos los cuales la adjudicación de grandes contratos, les abría la posibilidad de que de alguna u otra ma. nera, algo les caería a ellos. Los tiempos de la consolidación de la deuda interna, no habian sido todavía olvidados, pero sin embargo, había transcurrido ya largo tiempo desde la caida de esta lluvia de oro, siendo cada vez más vivo y urgente el deseo de que se encontrase una oportunidad para que se i epitiese lo que se había vivido el año cincuenta, bajo la presidencia del señor Echenique. Pues Castilla, que fue sucesor de Echenique en su segundo mandato, no fue de ninguna manera económico con el dinero del fisco, sólo que no permitió de ninguna manera el soborno y el fraude; San Román gobernó sólo seis meses, muriendo sin mácula; en el período del general Pezet que lo reemplazó como primer vicepresidente, ocurrieron, sin duda, irregularidades, de las que, no obstante, pocas personas sacaron provecho. Luego vino Prado, cuyo primer período se distinguió por el desinterés y una administración concienzuda. Después de que Prado emprendiera una campaña contra la insurrecta Arequipa, con tan lamentable desenlace, debiendo huir a Chile, le sucedió su vencedor, el general Pedro Diez Canseco, a quien, como a segundo vice- 
presidente, le correspondía todavía un período de gobierno de algo más de seis meses. El y sus partidarios decidieron utilizar este corto tiempo para explotarlo en lo posible. Estando ya en camino a Lima, y aun antes de haber llegado a la capital, se insinuó el pensamiento de iniciar entonces la construcción, del ferrocarril a Arequipa, para lo cual va había sido facultado desde hacía tiempo por el Congreso. Todavía no se había negociado dos millones de libras esterlinas del empréstito de 1865, que se había levantado en tiempo de la guerra con España, estando todavía esta suma a disposición del gobierno. Tanto para llevar a cabo inmediatamente la ejecución técnica de la empresa, como también para asegurar el provecho propio al negociarse el contrato, se invitó al empresario de construcciones, de nacionalidad norteamericana, Henry Meiggs, quien se encontraba en Chile a la sazón, a venir a Lima para solicitar el contrato. Como este hombre, desde su llegada al Perú hasta su muerte, durante diez años, había ejercido una influencia casi decisiva en la vida pública y privada, interrumpiremos por ahora el hilo del relato, a fin de ofrecer por anticipado una ojeada sobre su vida anterior.

Henry Meiggs nació el 1ㅇ de Julio de 1811 en Catskill, Greene Country, en el Estado de Nueva York. Su padre, Elías Meiggs, era contrațista de obras y había participado en muchas empresas públicas y privadas de importancia. Ya de muchacho, el joven Henry trabajỏi en el negocio de su padre, aprendió a dibujar y hacer planos y presupuestar costos. Sólo tenía doce años de edad cuando ya comenzó a desempeñarse en empresas independientes, y a pesar de su juventud $\mathrm{v}$ de estar entre personas mayores, consiguió un cargo estimable, gracias a su actividad y su precoz inteligencia. Más como las estrechas condiciones de su propio terruño pequeño no bastaban a sus aspiraciones, es por lo que, a la edad de 23 años (1834), se dirigió a Nueva York. Allí ingresó a un gran negocio de materiales de construcción, y demostró en ese puesto de responsabilidad ser tan hábil y activo trabajador, que a los tres años le ofrecieron ingresar como participante en la sociedad. Por ventajosa que fuese esa situsción, él la declinó, prefiriendo, en vista del conocimiento que tenía del mercado, utilizarlo en propias realizaciones. Trabajó con mucho éxito y se había ga. nado ya un apreciable capital, cuando le sobrevino el primer contraste. Por causa de una crisis financiera, en la que quebraron muchos bancos, Meiggs perdió también la mayor parte de su fortuna. Mas él sobrellevó su suerte con tranquilidad. Era joven, sano, gozaba de una buena reputación y del cré- 
dito correspondiente, y a breve plazo, empezó nuevamente a trabajar con buen éxito, poco después, abandonó Nueva York, y se instaló en la vecina Williamsburg. Allí obtuvo, además de un puesto de comercio muy importante, gracias a su gentileza y bonhomía, grandes relaciones sociales, de tal manera que, durante los últimos cuatro años de su permanencia, fue elegido allí presidente del Ayuntamiento, es decir que desempeñaba un puesto que correspondía al de nuestro primer alcalde. En tal función, alcanzó grandes merecimientos en los asuntos de la ciudad.

Meiggs era entonces un hombre acomodado y bien quisto, pero su círculo de acción erz., en realidad, lucrativo y honorable, aunque demasiado limitado para darle satisfacción. Como antes en sus tiempos de adolescente, su ciudad natal, Catskill, le pareció ahora en su edad de más vigor, Williamsburg, es decir, muy estrecha; anhelaba empresas mayores pari. poder demostrar lo que era capaz de rendir. Cuando, el año 1849 , se difundió la noticia del descubrimiento de las minas de oro de California, sintió que allí se le abría el campo hacia el cual había aspirado: renunció a su negocio y, como muchos otros, tomó el tren para el nuevo El dorado. Cuando ya fue un hombre conocido en círculos más amplios, ocupó él inmediatamente destacados puestos en California, desde el punto de vista comercial, y pronto también en la vida política. Emprendió en San Francisco unna serie de grandes empresas privadas y de trabajos públicos, junto a varios proyectos de calles, en especial la construeción de un gran dique portuario, que llegó a tener su nombre. En los cinco años de su permanencia, fue nombrado cuatro veces para el Ayuntamiento, siendo dos veces su presidente. El entonces muy poderoso partido dc California, Knownothing, cuyo fin principal era la margina.. ción de los extranieros de los cargos públicos, le propuso presentarlo como candidato para el cargo de gobernador, a lo que Meiggs, pese a todo, declinó, ya que la aceptación de ello no se compaginaba con sus intereses comerciales.

Mas esta aparente y gran prosperidad, de que entonces gozaba Meiggs, llevaba en su seno el geımen del infortunio, y sin duda del peor que este hombre había de encontrar en su vida, pues el fracaso que experimentó, no sólo tragó su fortuna sino perjudicó asimismo, su nombre, hasta ese momento sin tacha. La rapidez con la que hobía surgido la ciudad de San Francisco, la prisa y audacia de todas las empresas especulativas, no podían seguir mucho tiempo sin un tras- 
piés, en el que muchos bancos y firmas quebraron, y Meiggs, cuya fortuna había experimentado grandes daños a causa de incendios, fue una de las primeras en quebrar. El entonces general Sherman, que había de jugar posteriormente un rol importante en la guerra civil americana, había dejado, como muchas otras personas, la carrera que habían seguido hasta entonces, y había ingresado a una casa bancaria en San Francisco, en la esperanza de hacer rápidamente una fortuna. Estaba en relación comercial con Meiggs, y anotó en sus Memorias lo siguiente, relacionado con las circunstancias y acaecimientos de esos momentos: "En el año 1854, Henry Meiggs era principal accionista de la casa comercial en maderas de construcción Meiggs, Neeley \& Thompson. Era entonces uno de los hombres más en vista, vivía con gran tren de vida en Broadway, era miembro del Ayuntamiento y poseedor de un aserradero en la costa, en las cercanías de Mendocino. Nisbet, socio de Sherman en el negocio, tenía incondicional confianza en Meiggs, aunque Sherman no compartía de esta opinión, ya que estaba enterado de que Meiggs había aceptado también grandes sumas de otras casas. Por eso es que insistió en aue de los $\$ 80,000$ que debía éste a la Casa, 25,000 debían ser devueltos, debiendo ser cubierto el resto por una hipoteca de la residencia de Meiggs. Poco después, Meiggs y su familia desaparecieron, habiéndose sabido que se había embarcado rumbo a la América del Sur, en un barco de vela. Este fue el comienzo de una serie de bancarrotas, que se sucedieron unas tras otras en un lapso deedos años. Meiggs debía una suma próxima al millón de dólares. Como era miembro del Ayuntamiento, había aprovechado de esta posición para poner en circulación varios números de obligaciones de calles (street. scrips), lo que fue considerado como falsificación aunque la mayor parte, no todas, había sido suscrita en forma legal, pero empleada de una manera ilícita. Meiggs apareció nuevamente en Chile, volvió a conseguir otra vez biencstar y pagó muchas de sus deudas californianas, aunque nada a Sherman, cuya Casa, por lo demás, había perdido en street-scrips 10,000 dólares.

Meiggs desembarcó en Chile a principios del año 1855, en el tiempo oportuno, tanto para aprovechar a este país, como para hacer reflotar de nuevo la encallada embarcación de su fortuna. Por entonces, se había comenzado en Chile a construir los primeros ferrocarriles, que debían unir la capital con las regiones de su extendida costa. El ferrocarril del sur había sido acabado sólo hasta Rancagua, existiendo el temor general 
de que los constructores de entonces no estarían en capacidad para prolongar esos trabajos. Meiggs se ofreció, a poco de haber llegado, para prolongar, en un determinado tiempo, y a crédito, el ferrocarril hasta San Fernando, obra que llegó a ser un hecho, aun antes del tiempo fijado. Eso le había confirmado la reputación que le precedía, de ser un hábil y audaz constructor; y como la construcción del ferrocarril entre. Valparaíso y Santiago hacía muy penosos progresos, y cada vez se hacía más notoria la duda sobre su conclusión, todas las miradas se dirigieron hacia Meiggs. Este, que después de la terminación del tramo ferrocarrilero del sur se encontrú sin trabajo, le propuso, pues, al gobierno, emprender la terminación de la obra. Encontró en el que era ministro del Interior a la sazón y amigo del Presidente Montt, Antonio Vargas, apoyo caluroso, el contrato fue aprobado en la Cámara por unanimidad, siendo suscrito por Meiggs el 14 de setiembre de 1861. En breve plazo, todo había cambiado, desaparecieron las, en apariencia, invencibles dificultades y dos años después fue entregado el ferrocarril al servicio.

Como es natural, Meiggs había tenido en la ejecución de tan importantes trabajos la correspondiente ganancia como empresario, habiéndosele inculpado que ésta no fue utilizada ante todo para saldar la deuda que había dejado en San Francisco. Según los testimonios de Sherman, había amortizado algunas; pero Meiggs, que personālmente casi no tenía necesidades, se complacia vivir en gran tren, dejando que otros gozasen con lo qué a élele era indiferente. Se"mandó construir en las inmediaciones de Santiago una villa semejante a un palacio, rodeada de un gran parque y jardín, habiendo invertido en estos arreglos la mayor parte del dinero que había ganado. Mas como después de la terminación del último trabajo no se le ofrecieron otras empresas, comenzaron paulatinamente a hacerse muy estrechos los medios necesarios para el mantenimiento de un tan costoso nivel de vida. No podía vender su propiedad, puesto que no existía un comprador, razón por la que decidió organizar una lotería y ponerla en suerte. Se pusieron a la venta 700,000 suertes de a peso, no. sólo en Chile, sino en toda la costa del Pacífico, habiendo sido tomadas en realidad 400,000. Cuando Meiggs se convenció de que ya no se colocarían otras más, hizo obsequio de los restantes 300,000 a la ciudad, en hospitales y demás instituciones de beneficencia, y ordenó que se llevase a cabo el sorteo. Un antiguo empleado o dependiente de su oficina, fue el feliz ganador. Meiggs hizo llamar al joven a quien le preguntó qué es lo que pensaba 
hacer si encontraba un comprador para la casa. $\mathrm{Y}$ cuando el interrogado se negó a ello, su antiguo jefe le ofreció $\$ 80,000$, que el otro aceptó gustoso, con lo que emprendió viaje a Europa, en tanto que Meiggs siguió en la villa lo mismo que antes. Mas el resultado gue le quedó de la lotería, deducidos todos los gastos, no fue muy grande, y dados sus grandes gastos, comenzaba a quedarse sin nada. Fue entonces que recibió una invitación para venir al Perú y hacer proposiciones ai gobierno para la construcción del ferrocarril a Arequipa.

No era nuevo en absoluto el plan de unir Arequipa con la costa. Esta ciudad es después de Lima, la más importante y notable del Perú, su pueblo es trabajador, hábil para toda clase de oficios, espiritualmente despierto, siendo en este aspecto superior a los habitantes de las demás provincias del país, más por eso, y quizás si justamente por esa razón, fácilmente excitable, intranquila e inclinada constantemente a levantarse contra cada gobierno constituído. Es por ello que después de la explotación del guano, se encendieron los celos contra la capital, donde se gastó el producto de aquél, así como el constante corrosivo rencor por no adjudicárseles a las otras ciudades del país, y en especial a Arequipa, la parte que les correspondía de las riquezas del Estado. Como no se podía negar en el fondo la legitimidad de las reclamaciones de los arequipeños, y se les hacía generalmente el reproche de tener la avidez que sienten los hambrientos cuando ven constantemente ante ellos la canasta de pan, sin poder alcanzarla, accedió, pues, Castillá,epese ansul icóleraepor"la insurreción dé la ciudad, bajo Vivanco, (la debelación de la cual le costó a él y al país tan severos sacifificios), a dar su consentimiento para la construcción de un ferrocarril. Al finalizar su segundo período (octubre de 1860), se dio facultad al gobierno para que, lo más pronto que fuese posible, y en las condiciones más ventajosas para el país, se convocase a un concurso para la construcción de un ferrocarril de Islay a Arequipa. En seguida, en febrero del año siguiente, el Director de Trabajos Públicos, Mariano Felipe Paz Soldán, encomendó a dos jóvenes ingenieros, Federico Blume y Manuel Echegaray, examinar la zona comprendida entre Arequipa y la costa, y proyectar un trazo provisional de un ferrocarril y hacer una evaluación del costo. Estos ingenieros tuvieron que luchar contra grandes inconvenientes, siendo muy limitados los medios económicos que se habían puesto a su disposición. Pero no obstante ello, terminaron las tareas que les fueron confiadas en el relativamente corto plazo de 75 días, y tan bien, que su plan sir- 
vió de base a todos los trabajos posteriores, siendo ejecutado finalmente con muy escasas modificaciones. En todo caso, esto ocurrió sólo después de 18 años. Un año después de la aceptación del plan, el gobierno hizo un llamamiento para la fundación de una sociedad por acciones, a la que se le aseguró el pago de un seis por ciento, por la caja del Estado, por el capital invertido en la construcción, sin que nadie quisiera participar. El Congreso elevó luego a 7\% la garantía de intereses, y el Vicepresidente Antonio Pezet que sucedió a San Romnán, al fallecer éste, adjudicó a los señores Joseph Pickering (inglés) y Patricio Gibson (arequipeño) la concesión de la construcción, bajo la garantía del $7 \%$ sobre un capital a invertirse, de 8 millones de soles, el que fue aumentado posteriormente a 15 millones. Los adjudicatarios debían comenzar la construcción en el plazo de dos años a partir de la celebración del contrato, y terminarlo a los seis años. En caso contrario, se anularía el contrato, debiendo pagar los empresarios una multa de 50,000 soles a la Caja del Estado (12 de diciembre de 1864). Los adjudicatarios trataron de constituir una sociedad a base de su concesión (Sociedad de Ferrocarriles del Perú), lo que no dio resultado, de tal modo que al transcurir el plazo de dos años, les fue revocado el contrato, siendo condenados, bajo el régimen de Prado, al pago de la multa fijada (enero de 1867). Al ser desterrado Prado, llegó al gobierno el seguno Vicepresidente de San Román, general Canseco, quien, con el derecho que le daba la resolución legislativa de 1860, de sacar nuevamente a licitación la construcción del ferrocarril a Arequipaghizocvenir liconestesfin, desde Chile, a Henry Meiggs.

Aunque ya era cosa de antemano decidida, confiar a Meiggs la construcción del ferrocarril, no se podía hacer esto sin más preámbulos, sin haberse hecho antes las tramitaciones de rutina, entre las cuales estaban los informes del Tribunal de Cuentas, del Fiscal de la Nación y de la Comisión Central da Ingenieros, de todos los cuales, los dos últimos eran los más importantes. Antes de que Meiggs hubiese presentado su propuesta, ya lo habían hecho otros tres postulantes: Eduardo Harmsen, de Arequipa, en setiembre de 1867; Roberto Beddy, en febrero de 1868; Benjamín Bates, en marzo de 1868. Bates se ofreció a construir el ferrocarril por 7'000,000 de soles; Harmsen y Beddy, por 8'000,000 reunidos por una sociedad por acciones, en la que debía participar el Estado. El fiscal Gregorio Paz Soldán advirtió al gobierno que no celebrase contratos con personas que no pudieran ofrecer las necesarias 
garantías, especialmente con entidades por acciones, todas las que no habían traído hasta ahora sino desilusiones. En todo cso, tampoco Meiggs podía ofrecer otra garantía que su persona y su reputación como contratista, las que fueron consideradas como suficientes. El 31 de marzo presentó él su propuesta, que fue aceptada el 20 de abril, siendo suscrita notarialmente el 4 de mayo. En virtud de ella, se comprometía el contratista a terminar el ferrocarril desde la bahía de Mejía hasta Arequipa, de acuerdo a los planos de los ingenieros Blume y Echegaray, en un plazo de tres años a partir de la suscripción del contrato, y a garantizar las buenas condiciones de la línea, por tres años, aprobándole el gobierno, en cambio, el precio de 12 millones de soles, dos millones de los cuales debían ser puesto a su disposición en el extranjero para la adquisición del material necesario, y el resto de la suma a medida que se terminasen los tramos de la línea, o sea a razón de 100,000 soles por cada milla inglesa.

Llama la atención inmediatamente en este contrato, lo elevado de la suma aceptada para la construcción, ya que el presupuesto de Blume y Echegaray sólo llegaba a algo más de ocho millones, a siete el de Bates, y a ocho millones el de Harmsen y Beddy. Se le acordó, pues, notoriamente tanto más a Meiggs, cuanto que se le ponía en condiciones de disponer de las correspondientes sumas. En realidad, él distribuyó más de 1'800,000, recibiendo su parte desde el Presidente, los ministros y altos empleados, hasta los porteros de Palacio. Cuánto le correspondió àccada individuó, ces cosaque, naturalmente, no se puede señalar con exactitud. En Lima, donde todo sc divulga, se decía que el Presidente Canseco y el Presidente del Consejo de Ministros, Mariscal La Fuente, habían recibido cada uno 200,000 soles, y los demás ministros, la mitad. El autor no sabe a ciencia cierta sino lo que recibieron los ingenieros, pues uno de ellos se lo refirió; Federico Blume, el mismo que había trazado el primer plano, recibió entonces la recompensa de los trabajos de muchos años. Había sido él, bajo el gobierno de Pezet, miembro de la Comisión Central; había perdido su puesto baio el régimen de Prado, siendo perseguido y padeciendo en difícil situación. Mas ahora había sido repuesto en su cargo, en el aue fueron sus colegas, el norteamericano llamado Gerrit Barkus y el escocés Alejandro Prentice. Blume había trabajado anteriormente en Chile a las órdenes de Meiggs, por lo cual éste lo buscó apenas había llegado a Lima, para pedirle sin rodeos que lo apoyase con su influencia en su solicitud, a cambio de un honorario de 100,000 soles. 
Le hizo ofrecer por intermedio de Blume la misma suma a su compatriota Backus, quien lo merecía más, pues se encontraba enfermo en cama, sin tener nada que hacer, como no fuera firmar los documentos elaborados por Blume. El tercer miembro de la comisión, Prentice, mantuvo una actitud de rechazo, razón por la cual salió con las manos vacías, permaneciendo, pues, en la minoría, poniendo, finalmente, de balde su nombre bajo el dictamen.

Cuando Meiggs llegó al Perú, ya no tenía ningún dinero en efectivo, y hasta venía debiendo. Para atender los grandes obsequios a que se había comprometido con el fin de conse.. guir su contrato, lo que más le importaba era recibir lo antes posible una gran suma, cosa que él había preparado en una cláusula del contrato. En ésta se estipulaba que de los 100,000 soles que debian serle pagados por cada milla, que habrían $\mathrm{d} \approx$ serle abonados 70,000 al terrninar el trabajo del terraplén y 30,000 despiés de la colocación de los rieles. Mas no era necesario terraplenar nada en grando trechos de la pampa o de la elevada llanura de Islay, sino mas bien debía indicarse la dirección del carril mediante surcos en la arena firme. Apenas unas semanas después de haberse firmado el contrato, y mientras los escépticos de Lima se iban en suposiciones acerca de si los trabajos comenzarían ese año, Meiggs presentaba a la Tesorería de los ingenieros del gobierno recibos autenticados, según los cuales ya habían sido construídas 15 millas de calzada para la colocación de-los rieles, yeporlo cual solicitaba 1'050,000 soles que, J de acuerdo donceh contrato, le correspondían. Con eso hizo los primeros pagos a sus favorecedores, quienes podían estar convencidos en lo sucesivo, que no se habían equivocado con él. Hasta el ingeniero Blume, que hasta poco antes apenas si tenía unos reales para enviar al mercado se compró poco después dos casas; y su colega Backus usó el dinero de manera menos juiciosa, pues bebió hasta matarse.

En la primera mitad del año 1868, Lima fue afligida por segunda vez con la fiebre amarilla, contagiándose también c] mismo Meiggs, aunque en ligera forma. Pero el público, que no podía tener ninguna idea acerca del carácter de la enfermedad, cayó en gran confusión. Todas las mañanas había centenares de hombres ante su puerta, y cuando el autor salió de la casa, fue asaltado con preguntas. De la mayor o menor inquietud con que se recibían los informes, se infería claramente quién había recibido ya algo y quién estaba esperando todavía su parte. La calle en la que vivía Meiggs por ese enton- 
ces, era bastante tranquila, pero sin embargo, fue clausurada para toda clase de vehículos por orden del Prefecto, y también les fue prohibido a los frailes del próximo convento de los mercedarios, por mandato del Arzobispo, repicar sus campanas. Estas campanas católicas, que se rasaban entonces repiqueteado todo el día, tuvieron, pues, que enmudecer, a fin de no molestar los oídos del respetable hereje. La oración que elevaban muchos piadosos, invocando entonces a los santos protección para su benefactor, no permaneció mucho tiempo sin ser oída. Después de una dolencia de diez días, Meiggs se levantó de la cama, y para reponer su salud, emprendió viaje a Chile, por algún tiempo. Allí demostró muy pronto que no inmerecidamente gozaba de la simpatía general de que entonces se veía rodeado, pues al producirse el gran terremoto del 13 de agosto de 1868 , que puso en ruinas las ciudades del sur, hizo donación al gobierno, de su peculio, de la suma de 50,000 soles para socorrer a los damnificados.

Había transcurrido entre tanto el período de gobierno del Vicepresidente Canseco, habiendo asumido el poder el recién elegido para la Presidencia, D. José Balta. Dreyfus celebró su contrato del guano con el ministro de hacienda de Balta, Nicolás de Piérola, que luego fuera el dictador en 1880. Meiggs, que ya había trazado sus grandes proyectos, reconoció en Dreyfus a un hombre que en asuntos de finanzas tenía tanta visión y audacia como él como contratista de obras. Los intereses de ambos eran lostmismos: y hasta es improbable que Drevfus șe hubiese empeñado en el riesgoso contrato, si no hubiese aprendido en el ejemplo de Meiggs, qué es lo que se. puede conseguir en el Perú, y por qué medios. Lo que indujo sobre todo a éste a vincularse con Dreyfus, fue la perspectiva de los grandes empréstitos que ya estaban preparados entonces, y de cuya realización dependía la posibilidad de ulteriores empresas ferrocarrileras.

No obstante haber gastado Meiggs grandes sumas del dinero de la construcción, ésta había sido tan liberalmentc evaluada, que el sobrante podía contentar a un hombre de no escasas exigencias. Meiggs, empero, no veía en ello sino el primer peldaño de la escalera que debía de conducirlo a la plataforma de su grandeza. Ya al finalizar el año, le fue confiada la construcción de dos grandes líneas que debían trasponer los Andes: una, de Arequipa hasta Puno, y la otra, de Limit hasta el valle de Jauja, o de acuerdo con la corriente designación, hasta el puente de La Oroya sobre el río Mantaro. La 
fiebre ferrocarrilera había hecho presa de todo el país. Meiggs, que había visto la influencia de los medios de transporte en el desarrollo de las nuevas zonas y en el aumento de la población en los Estados Unidos, consideró como posible y probable una influencia semejante en el Perú. Y él se equivocaba, pues dejó de ver la total diferencia del carácter de la población, mas como los puntos de vista expuestos por él con toda convicción. halagaron los sentimientos nacionales de los peruanos, y como aquéllos fueron apoyados, además, por una ilimitada liberali. dad, se entregaron gustosos a una ilusión, que poco a poco degeneró en un delirio. Se tenía a Meiggs por un hombre enviado por la divina providencia, que habría sido llamado para terminar con los insanos tiempos de las querellas intestinas, e implantar una era de progreso general. Fue depositada en su mano la fortuna del Estado, sin otra garantía que la confianza en su personalidad; y se olvidó que su liberalidad no era otra cosa, al fin de cuentas, que el obsequio, no de su dinero, sino de los medios puestos a su disposición, pudiendo decirse que se convirtió en el gran limosnero de la República.

En todo esto no descuidaba el influir ocasionalmente en la imaginación del pueblo. No bien hubo recibido (a fines del año 1860) la concesión para la construcción del ferrocarril a La Oroya, que ya se puso solemnemente la primera piedráa de la estación (enero 19 de 1870) como inicio de los trabajos. Para tal fin se llevói una piedra labrada a la parte baja de la ciudad, la que fue colocada sobre la arena. El Presidente, sus ministros, los cónsejos de los tribunales supremos, las altas autoridades, la comisión del Congreso, los generales y todas las personas que tenían entonces alguna influencia salieron en procesión solemne para ver la piedra y asistir a la consagración. El ya muy vieio arzobispo (Goyeneche), quien desde hacía años tenía un pie en la tumba, tuvo que sacarla nuevamente, vacilante, para bendecirla. Luego, el Presidente golpeó con martillo de plata sobre la mencionada piedra y valido de un badilejo de plata, embadurnóla con mortero (habiendo manifestado algunos que el mortero también era de plata), distribuyéndose en seguida entre los más distinguidos asistentes medallas de oro, cada una de las cuales valía 400 marcos; y todos cuantos habían visto las herramientas de plata y las medallas conmemorativas de oro, lanzaron al aire sus sombreros y rompieron en exclamaciones de júbilo, exactamente como si la gran vía férrea, que todavía no había sido comenzada, cstuviera ya concluída. Y por si acaso hubiese todavía algún desconfiado que no quisiera creer en la ejecución de la 
obra, se sirvió después de la ceremonia un banquete para 800 invitados, costando 25 soles (100 marcos) el cubierto, lo que era suficiente, en realidad, para convencer a los escépticos más empedernidos. La sala para la fiesta fue arreglada en el patio de la Escuela Militar de entonces, y adornada con gusto. En las columnas envueltas en guirnaldas colgaban escudos de la República en medio de estandartes; el techo era de loná velera, y debajo de todo, en las cornisas, lemas alusivos al progreso, el trabajo y la libertad. Había en la sala innumerables mesas con preciosos adornos de flores, magníficos centros de mesa, sobre los cuales había todos los platos posibles y vinos de calidad, de modo que, en verdad, era de asombrarse de cómo aquello había sido arreglado en tan corto tiempo. La sala comenzó a llenarse después de las cuatro, siendo las mesas ocupadas, y cuando e! Presidente tomó asiento en su sillón de honor, detrás de una enorme locomotora de azúcar, se hizo oir el Himno Nacional. Estaban presentes tres coros de música, y como todos tocaban al mismo tiempo, habiendo comenzado en diferente momento, se hizo un ruido endemoniado, que correspondía completamente a esta fiesta. El calor del verano, el vino, la cantidad de discursos y speeches crearon muy pronto una pesada atmósfera; poco a poco se elevaron tanto las olas patrióticas, que el autor pudo dirigirse a la salida, sólo lentamente y con dificultades, poniéndose al fin fuera de la tormenta. Se dirigió a Chorrillos, y paseando por el malecón, iba recordando, en su soledad, lo ocurrido, pensando en cómo terminaría fedo esto. Hemos visto desnués a qué condujo todo estog aün antes de davguerra con Chile. El ferrocarril, cuya construcción fue entonces inaugurada tan pomposamente, no ha sido terminado hasta ahora. como tampoco los restantes, que fueron emprendidos simultáneamente.

No se quiere decir con eso que atribuyamos a Meiggs la no terminación de los trabajos emprendidos; él los habría ter minado mientras vivía, si el gobierno hubiese cumplido las obligaciones contraídas con él. Pero tampoco se le puede absolver de los reproches de haber usado su extraordinaria influencia, de manera deplorable, pensando menos en la verdadera salud del Estado que en su propio encumbramiento y precipitando la ruina del país a causa de sus desmedidos gastos, y como comenzó todas las obras simultáneamente, impidió que se concluyese alguna. Ya veremos después cómo estos desaciertos se vengarían del mismo Meiggs, pues, a la meta que tendía no le fue dado llegar; el monumento que con la construcción del ferrocarril sobre los Andes quiso eri- 
girse, no fue levantado, y ni siquiera el modesto mausoleo que debía indicar el lugar de su descansc.

De todos modos, llevó a la conclusión una obra, para la cual había sido llamado al Perú: el ferrocarril a Arequipa, y en realidad, cinco meses antes de lo que le obligaba el contrato. Si no hubiese cumplido el plazo señalado de tres años, ya se había declarado estar listo a pagar por cada mes más de 20,000 soles pero en cambio se había puesto como condición un premio igualmente alto, en caso de que lograse terminar la obra antes, pudiendo pues exigir, en todo caso, en ese momento, una recompensa relativamente insignificante. La terminación del ferrocarril en el tiempo indicado, era ciertamente un excepcional esfuer\%o, y para hacerlo posible, ha bría sido necesario modificar algo el plano original trazado por Blume y Echegaray. La extendida y arenosa llanura entre Arequipa y la costa, termina en su límite superior, que da a la ciudad, en una fila de alturas rocosas, la que Blume creyó necesario atravesar con un túnel. Meiggs no tenía necesidad de usar este túnel, pues su perforación no le habría permitido cumplir con el plazo fijado. Declaró, pues, a sus ingenieros que había que encontrar otro camino, y es en esta oportunidad que se habría hecho presente personalmente en la línea. Pues Meiggs, como el difunto Alfredo Krupp, no hacía nada que pudiera ser hecho por otros, y siempre se limitaba, en lo posible, a la tarea de dirigir y decidir. Poseía un equipo de inteligentes y probados ingenieros, en el que podía descansar toda su confianza. Y sècencontró ure huevo trazo, en realidad. En lugar del túnel, se hacía unıa serie de serpenteos y profundos cortes en una roca muv dura. Este trecho fue trabajado simultáneamente en varios ountos por disposición de Meiggs, mientras que en un túnel sólo un limitado número hubiera podido trabajar por ambas partes. La gran mayoría de esta gente era de Chile, quienes ya habían trabajado antes a sus órdenes, y le eran completsmente adictos.

Meiggs no se vanagloriaba nunca de su éxito, pero mencionaba a veces la fidelidad de sus trabajadores con una satisfacción que denotaba su íntimo orgullo. Debía pensar, de seguro que para esta modestísima clase de sus colaboradores conservaba en su corazón más gratitud y verdadero afecto que para muchos otros que habían recibido de él grandes sumas de dinero y habían hecho muy poco por él. De todos modos, eran mejor pagados de lo que estaban acostumbrados en su país, y, prescindiendo de su salario, Meiggs cuidaba entonces 
de ellos en forma paternal, de tal modo, que estos mozos siempre pendencieros y listos para peleas sangrientas, se mostraban junto a él pacíficos y en todo momento dóciles. Generalmente, Meiggs era bien atendido en ese sentido, ya que él sabía escoger su gente, y le gustaba recompensar sus servicios en una forma que podía llamarse principesca, si todavía hubiera príncipes en nuestro tiempo que pagasen como él lo hacía. Su ingeniero principal Thorndike recibió un sueldo anual de cuarenta mil soles (150.000 marcos), y su superintendente, Joseph Hill, recibió todavía más. Los sueldos de todos los empleados eran tan copiosos, que cada uno podía hacer economías.

El 24 de diciembre de 1870, se terminaron los trabajos del ferrocarril, habiendo decidido Meiggs entregárselo al gobierno antes de fin de año. Esta ceremonia constituyó el punto más brillante de su carrera en el Perú. Invitó para ella al Presidente, a los ministros, a muchos senadores y diputados, así como al Cuerpo Diplomático, recibiendo su respuesta afirmativa. El círculo oficial de los invitados debía de dirigirse en buques de guerra al puerto recientemente construído de Mollendo, mientras Meiggs había arrendado el Panamá para sus amigos personales y relacionados, siendo en ese tiempo el barco más grande y hermoso de la compañía inglesa. Nunca se había visto en la estación de Lima un apretujamiento tan grande, pues junto a los cientos de participantes, se hallaban presentes muchos más que ibari hasta el Callao, acompañándolos, y para ver la partida de los buques on El Ranamá permaneció mucho tiempo echando imuacientemente vapor, sin poder hacerse a la mar, pues la etiqueta prescribía que la corbeta Chaiaco, en la que deseaba embarcarse el Presidente, debía estar al medio del Panamá y algún otro vapor hasta ser conducida fuera de la bahía, luego de lo cual sería seguido por los dos buques de guerra. Por fin, a eso de las cinco de la tarde, una chalupa a vapor trajo a bordo a las personas principales de la fiesta, zumbaron las salvas de saludo de los fuertes, los marineros se mantenían en filas oscuras en las vergas y exclamaban: Hip, hip, Hurra, y entonces comenzó a bullir el agua bajo nuestros barcos. La breve travesía en el Panamá parecía un cuento árabe. La cubierta estaba iluminada por centenares de linternas multicolores, a par que la luna rielaba en la tranquila superficie del mar. Un conjunto de músicos tocaba alternativamente piezas de concierto y de danza, y los caballeros y las damas, de pie o sentados, conversaban en animados grupos. Todo cuanto era posible proporcionarse en la 
bien provista Lima, en materia de ricas viandas y bebidas, se encontraba allí, adquirido por el dispendioso anfitrión, pues no obstante de que él mismo no probó casi nada, hubo de alegrarse con el apetito y satisfacción de sus huéspedes. Menús impresos ilustraban a aquéllos acerca de lo que podían desear, y junto a cada cubierto había una linda tarjeta en la que, en letras de oro, estaban indicados los platos de las comidas. Se había tenido cuidado especial para los aficionados al cham. paña, ya que las mejores marcas estaban en hielo, noche y día.

El 29 de diciembre llegó a vista de Mollendo, a las 9 de la mañana, y después de 36 horas de travesía, el Panamá; viaje rápido del que estaba orgulloso el capitán, aunque para otros había apurado demasiado, ya que se hubieran querido quedar más tiempo a bordo. La corbeta Chalaco con el Presidente, llegó sólo a eso de las dos de la tarde, y los demás buques de guerra, mucho después. Al anochecer, vino a tierra el mayordomo del Panamá, acompañado de sus cocineros y mozos, a fin de disponer los preparativos para el gran bariquete que debía ofrecerse al día siguiente. Con tal objeto fue improvisado sobre los roquedos de la playa, mediante tablas $\mathrm{y}$ tocuyos, un gran hall, el que, junto a algunas chozas, era entonces el único edificio de Mollendo. Detrás de este hall v delante de algunas barracas que fueron arregladas como cocinas, se sacrificó una inconmesurable cantidad de aves, habiendo grandes montones de gallinas, patos $\mathrm{y}$ pavos desplumados delante de la puerta, extendidos en el suelo. Trabajadores, cubiertos de malos Jponchos, merodeabañ por allí, y venían a veces como por casualidad, bastante cerca, para levantarse una pieza y meterla dentro del poncho. Nadie ponía atención a ésto iy para qué?, pues el hombre que disipaba millones, bien podía permitir que un pobre diablo se robara una gallina.

Al día siguiente de la llegada, tuvo lugar la bendición de las máquinas y de la Estación. Toda la comitiva bajó desde las alturas del hall a la orilla del mar, donde, sobre varios rieles, había ocho o diez locomotoras encendidas, juntas o una detrás de otra. Con la acostumbrada alocución, las bendijo el obispo de Puno, rociándolas con agua bendita, luego de lo cual, todas juntas, a la manera de las máquinas americanas, lanzaron un tremendo silbido, que fue repetido por los encantados espectadores. Después de esta ceremonia, se dirigieron nuevamente hacia las aireadas alturas, donde los invitados fueron buscando su sitio en el hall de la fiesta. La parte posterior del hall tenía un plataforma, sobre la que había una lar- 
ga mesa para los huéspedes principales. Tomaron en ella asiento el Presidente, los alins dignatarios, militares y senadores. Al pie de esta plataforma corrían paralelamente cinco o seis largas mesas, habiendo todavía junto a las paredes muchas mesas pequeñas. Transcurrió el banquete, como era de esperarse en esas circunstancias, en un ambiente de alegría que fue realzada por los buenos vinos. Naturalmente, se pronunciaron muchos discursos, pues en eso son incansables los peruanos, siendo asombroso ver qué capacidad tienen en tales ocasiones para decir y oir tantos disparates. Un día antes, el Presidente fue saludado en cxtensos discursos por los diputados de Arequipa; la mañana de la bendición hablaron los sacerdotes, los dipıomáticos y senadores, pero sólo ahora se produjo la verdadera batalla oratorial. Estas efusiones de aburrida palabrería vacua, se hicieron, finalmente, más raras, pero fueron seguidas de brindis, llegando a ser más vivaz la conversación. Muchos se levantaban de sus asientos para charlar con sus conociaos, mas de repente se dio cuenta la concurrencia de que el hombre del día, el anfitrión de la fiesta, no estaba en ninguna parte. Cundió un solo grito: ¡Don Enrique! Los peruanos no podían pronunciar el nombre de Meiggs, razón por la que siempre lo nombraban por su nombre de pila.

Cientos de voces corearon: ¿Dónde está Don Enrique? Había llegado uno de los grardes momentos en la vida de este hombre. Lo descubrieron en uno de los ángulos de la sala, en el que estaba sentado junto a un grupo de ingenieros. En un momento lo levantaron silla yetodo sobre la mesa, la mesa también fue levantada, y de esta manera, Meiggs fue llevado en triunfo, entre ensordecedores aplausos, hasta la plataforma. Este suceso y el motivo que lo originó son característicos del hombre que asi era festejado. Si él hubiera tomado asiento en la mesa de honor, que le correspondía como anfitrión, junto o al frente de los invitados de honor, el Presidente o el obispo, lo habrían criticado muchos con malignidad como advenedizo, pero como parecía avergonzarse de su suerte, ocultándose en un modesto rincón, aplacaba toda envidia en su raíz.

Meiggs era ambicioso, y sin duda en grado extraordinario, pero no como otros hombres, sino a su manera. Tendía al poder y a la influencia, pero no para distinguirse exteriormente, sino para evitarlo. Ganar dinero no era para él, en verdad, cosa accesoria, aunque sí un medio para su objetivo. Como extranjero, no podía desempeñar el más elevado cargo del 
Estado, y es por eso que decidió ser algo más que Presidente, lo que llegó a conseguir y seguir siendo, toda su vida. Aun en el más alto punto de su poaer, no cambió de conducta; peimaneció sencillo, cortés y alegre para todos. Era el primero en saludar y nunca trató de poner a su persona en primer plano. Esta modestia, junto a su prodigalidad, explican su éxito sin par en un país en el que la mayor parte de los hombres son envanecidos y exigen más de lo que les corresponde en e! aprecio exterior. Meiggs disponía de la fortuna del Estado, sin ser envidiado. Se envidiaba más bien a los que habían recibido mucho de él, pero no a él mismo. Nadie hablaba mal de él. Pero en todo caso, pagaba bien caro esta benevolencia. Ya veremos después a qué precio.

En la mañana del 31 de diciembre viajaron a Arequipa los huéspedes invitados. Cinco trenes partieron uno tras otro de la estación, viéndoseles una hora después en el gran desarrollo de los zigzags de la subida, viajando uno tras de otro, alternativamente, yendo en direcciones opuestas. Media población esperaba en Arequipa la llegada, siendo ilimitada la alegría y excitación de las gentes. Se sucedieron series de bai les y festejos de toda clase, y sólo al cabo de ocho días, cuando los invitados retornaron a Lima, la entusiasmada ciudad recobró su calma.

Luego que Meiggsihubocmostrado to que era capaz de rendir, se le confió por cuenta del Estado la construcción de los siguientes tramos de ferrocarril:

\section{Millas inglesas Soles}

\begin{tabular}{lrr} 
De Arequipa a Puno & 232 & 32.000 .00 \\
De Puno al Cuzco & 180 & \\
Del Callao a La Oroya & 130 & 27.600 .00 \\
De Ilo a Moquegua & 63 & 6.700 .00 \\
De Pacasmayo a Guadalupe & 14 & 2.700 .00 \\
De Pacasmayo a Magdalena & 69 & 5.000 .00 \\
\hline
\end{tabular}

O sea un total de cerca de 300 millones de marcos por todos estos trabajos públicos.

Por la mayor parte de estas empresas, en lugar de pago, tomó Meiggs bonos de la deuda de los nuevos empréstitos, 
con un cierto tanto por ciento. El costo del ferrocarril a $\mathrm{Pu}$ no había sido estimado demasiado alto, pues csta vía no tenía que vencer ninguna dificultad extraordinaria, razón por la que se ganó mucho en ella. En cambio, en la vía a La Oroya, fueron apareciendo. a medida que se construía, que las dificultades eran mucho mayores de lo previsto, habiendo costado ella bastante más de lo presupuestado. Como esta obra era justamente la que Meiggs tenía más a pecho, hizo que prosiguieran los trabajos, todo cuanto fuere posible, y al fin de cuentas con grandes sacrificios, hasta que, obligado finalmente por la estrechez financiera en que se debatía el Estado, hubo de paralizarlos. Ya en 1875 comenzó a vacilar el crédito del Perú, y después de haberse dejado de pagar los intereses al 30 de junio de 1876, bajó el cambio del empréstito rápida e inconteniblemente. A fin de procurarse dinero en efectivo, recurrió Meiggs a la emisión de papel-moneda por intermedio de la sociedad fundada por él (Compañía de Obras Públicas). Se emitieron más de cinco millones, pero el público se había vuelto desconfiado y adoptó una actitud negativa; y aún después, cuando el Estado asumió la garantía de esa emisión, apenas si rindió la mitad, pues el valor del papel-moneda cayó bastante, justamente a causa de esta medida del gobierno.

Meiggs se vino entonces cuesta abajo, y lo desenfrenado de su dilapidación se vengó de él y es posible que le hubiera pesado. Si hubiese vivido mucho tiempo, habría caído seguramente, si no precisamente en la pobreza, de cierto en esos grandes apuros en đque Se cencontrabavcuando llegó al Perú. $\mathrm{Su}$ muerte le ahorró sobrevivir al total descalabro de su otrora magnificencia, y dejó solamente a sus herederos nada más que reclamaciones al gobierno, y que éste, pese a su buena voluntad, no pudo satisfacer. Que con las ingentes sumas que Meiggs había ganado en sus contratos, fuera posible tal co$\mathrm{sa}$, es algo que se esclarecerá con los datos que siguen. Diez años después de la muerte de Meiggs (16 de setiembre de 1887), gracias a la amabilidad del señor Carlos Segundo Watson, ht jo del heredero legal y representante del heredero del desaparecido Henry Meiggs, Carlos Watson, le fue presentado al autor el libro mayor del año 1874, según el cual la suma total distribuída por Meiggs en regalos, gratificaciones, sueldos y pensiones hasta el 31 de diciembre de este año, ascendía a 10 '840,000 soles. Después de 1874, Meiggs no celebró ningún otro nuevo contrato, por lo que no tuvo necesidad de dar más gruesas gratificaciones, exceptuando la oportunidad de la em:sión de su papel-moneda, y posteriormente, cuando el gobier 
no de Prado asumió para el Estado estos billetes, a par que los de los bancos. Hav que aceptar por eso que el total de la suma distribuída por Meiggs asciende notablemente a más de once millones. Por su caia se pagó a un gran número de personas, públicamente, las cantidades que les estaban asignadas. consignándose sus nombres en los libros. Sin embargo, las sumas más grandes fueron anotadas en un libro secreto, el que estaba encerrado en una pequeña caja de hięrro, conservada en un gran armario del mismo metal. Este importantísimo libro le fue también mostrado al autor: un pequeño tomo en cuarto con lomo de cuero rojo, con las esquinas bastante gastadas por su uso frecuente. En este libro no se encuentra nillgún nombre, sino solamente números desde el 1 hasta 96. En una solapa del libro se halla la lista de las personas que corresponden a estos números. La cantidad más grande, o sea 1'145,000 soles, fue recibida por el abogado J. M. Q., en todo caso no sólo para él, sino para ser distribuída a muchas otras, especialmente a miembros del Congreso. Si echamos ahora, para terminar, un vistazo retrospectivo en la carrer? de Henry Meiggs, reconoceremos lo que hasta sus adversarios no pueden negarle: que era un hombre de inhabitual espíritu de empresa, de aguda visión comercial y de infatigable actividad; que ha rendido algo grande, aunque para sí otros habría rendido algo mejor, si hubiese sabido moderarse y si su conciencia, en lo tocante a los medios utilizados en sus empresas, hubiese sido menos amplia. Personas que habían conocido mucho tiempo a Meiggs, decían de éleque había tenido desde un principio predilección por los caminos torcidos y una inclinación al derroche. Pero sus faltas eran, justamente, las que lo hicieron tan apreciado en el Perú, y sin las cuales no hubiera llegado, seguramente, a la posición que ocupó casi a su llegada al país; Perú era el país que él necesitaba y él era el hombre que los peruanos deseaban. Meiggs era, seguramente, bondadoso de naturaleza, así como dadivoso, mas en todo lo que dio a muchos, no fue nunca su preocupación hacer un beneficio, ejecutar algo bueno por su propia voluntad, sino, mas bien, no perder la vista un objetivo inmediato o lejano, pero constante en todo ello. Lo que lo impelía no era tanto la ambición en el sentido corriente, sino comprometer, en lo posible, aun gran número de personas y hacerlos en cierto modo, dependientes de él, y tenerlos, en consecuencia, en su poder. Mas estos vínculos resultan débiles con el tiempo, especialmente si no se aseguran de tiempo en tiempo, o mejor dicho, si no se renuevan. Es esto lo que turo que experimentar Meiggs, y en especial al fin de la etapa ha debido sentir amar.. gos desengaños. 
En su vida privada y de familia, Meiggs no encontró apoyo alguno, ni en los tiempos de su esplendor, ni posteriormente, cuando la suerte le volvió la espalda. Vino ya viudo al $\mathrm{Pe}^{-}$ rú y trajo tres hijos adultos y una hija todavía niña. No parece que los hijos hubiesen heredado las facultades del padre. Eran inactivos, indiferentes, y mientras su padre era extremadamente moderado en todas circunstancias, los tres hijos se dieron a la bebida. Jamás ayudaron a su padre en sus trabajos, y parece que éste no intentó nunca tampoco ponerlos al trabajo. Tenía una gran estimación por la hija mayor de su hermano John, que estaba al frente de su oficina en Lima: una muchacha precoz y muy bien dotada, de 13 años de edad, a la que acostumbraba contarle todo su tío, lo que entonces no confiaba a nadie, pues este hombre extraordinariamente callado y reservado, tenía a veces la necesidad de expandirse sin rodeos. La muerte de esta muchacha, ocasionada por una fiebre palúdica, fue quizá la más grande pena que Meiggs hubo de sobrellevar durante su permanencia en Lima. El año 1876, se enfermó Meiggs con erisipela a la cabeza. Parece que nunca llegó a reponerse completamente de este ataque. Un año después se agudizó su antigua enfermedad al corazón, que lo llevó a la tumba después de una prolongada y dolorosa etapa. Recibió con beneplácito a la muerte. En su lecho de dolor, nunca expresó rener esperanzas de sanar, y mas bien les repetía frecuentemente a sus amigos íntimos, en tono tranquilo y resignado: yo quisiera morir. Este deseo se cumplió por fin el 30 de setiembre de 1877. Fue acompañado hasta el fin por la simpatía y adhesión declos habitantes de Lima. Fue enterrado con grandes honras fúnebres, habiendo sido sepultadn su ataúd en su propiedad Villegas, en el Callao.

(Traducción directa del alemán por Ernesto More). 